\title{
Atribut yang Menjadi Pertimbangan Konsumen Terhadap Minuman Kemasan Mengandung Ekstrak Jahe (Zingiber afficanate) di Kabupaten Sleman
}

\section{Attributes that are Considered by Consumers on Packaged Drinks Containing Ginger (Zingiber afficanate) Extract in Sleman Regency}

\author{
Hidayatus Shohimah Achmad dan Marosimy Millaty* \\ Universitas Nahdlatul Ulama Yogyakarta \\ Jalan Lowanu No.47, Sorosutan, Kec. Umbulharjo, Kota Yogyakarta \\ Daerah Istimewa Yogyakarta \\ email korespondensi: *marosimy@unu-jogja.ac.id
}

Diterima tanggal : 26 Desember 2021 ; Disetujui tanggal : 30 Desember 2021

\begin{abstract}
This study aims to determine what attributes are considered by consumers towards packaged drinks containing ginger extract. Data collection was carried out for three months (June-August 2021). Research respondents were people of Sleman Regency who consumed packaged drinks containing ginger extract. The number of research samples was 96 people, where the number of samples was obtained by calculating using the Slovin formula. Sources of data in the form of primary data and secondary data. Primary data was obtained from direct interviews with selected respondents while secondary data was obtained from several reference sources (books and journals). The data obtained were then analyzed using descriptive analysis to determine the characteristics of the respondents. To determine the attributes that are considered by consumers, a binomial test analysis is carried out which is processed using SPSS tools. Based on the results of the study, it is known that if consumers get packaged drinks containing ginger extract by buying at supermarkets (17\%), mini markets (26\%), grocery stores (41\%),online (5\%),others (13\%). In addition, the majority of consumers like to buy packaged drinks containing ginger extract in the form of sachet packaging, which is as much as $84 \%$. Furthermore, the binomial test is carried out to determine the attributes that are considered by consumers. Based on the results of the binomial test, it is known that the attributes of price, taste, packaging, product information, expiration, brand, promotion and accessibility are attributes that are considered by consumers in deciding to buy packaged drinks containing ginger extract.
\end{abstract}

Keywords: Attributes, Preference, Binomial Test.

\section{ABSTRAK}

Penelitian ini bertujuan untuk mengetahui atribut apa saja yang menjadi pertimbangan konsumen terhadap minuman kemasan yang mengandung ekstrak jahe. Pengambilan data dilakukan selama tiga bulan, yakni bulan Juni-Agustus 2021. Responden penelitian adalah masyarakat Kabupaten Sleman yang 
Achmad \& Millaty, Atribut yang Menjadi Pertimbangan Konsumen Terhadap....

mengkonsumsi minuman kemasan mengandung ekstrak jahe. Jumlah sampel penelitian sebanyak 96 orang, dimana jumlah sampel diperoleh dengan menghitung menggunakan rumus Lemeshow. Sumber data berupa data primer dan data sekunder. Data primer diperoleh dari wawancara langsung kepada responden terpilih sedangkan data sekunder diperoleh dari beberapa sumber referensi seperti buku dan jurnal. Data yang diperoleh selanjutnya dianalisis menggunakan analisis deskriptif untuk mengetahui karakteristik responden. Sedangkan untuk mengetahui atribut yang menjadi pertimbangan konsumen, dilakukan analisis uji binomial yang diolah menggunakan alat bantu SPSS. Berdasarkan hasil penelitian, diketahui jika konsumen memperoleh minuman kemasan yang mengandung ekstrak jahe dengan cara membeli di swalayan (17\%), mini market (26\%), toko kelontong (41\%), online $(5 \%)$, lain-lain (13\%). Selain itu, mayoritas konsumen menyukai membeli minuman kemasan mengandung ekstrak jahe dalam bentuk kemasan sachet, yakni sebanyak $84 \%$. Selanjutnya dilakukan uji binomial untuk mengetahui atribut yang menjadi pertimbangan konsumen. Berdasarkan hasil uji binomial, diketahui jika atribut harga, rasa, kemasan, informasi produk, kadaluarsa, merek, promosi dan kemudahan didapat merupakan atribut yang menjadi pertimbangan konsumen dalam memutuskan untuk membeli minuman kemasan yang mengandung ekstrak jahe.

Kata kunci : Atribut, Preferensi, Uji Binomial.

\section{PENDAHULUAN}

Minuman merupakan salah satu kebutuhan dasar setiap manusia. Cukup banyak produk minuman yang diproduksi oleh produsen minuman, salah satunya minuman instan. Minuman instan adalah minuman yang dapat langsung diminum dengan cara diseduh dengan air matang, baik dingin maupun panas. Salah satu ekstrak yang menjadi bahan campuran dalam minuman instan adalah ekstrak jahe. Selain digunakan sebagai bahan dasar dalam membuat produk minuman, jahe (Zingiber afficanate) merupakan salah satu jenis rempah-rempah yang banyak digunakan sebagai bumbu penyedap makanan, ramuan obat-obatan dan lain-lain (Setiawan \& Pujimulyani, 2018).

Jahe sebagai salah satu bahan dasar produk minuman kemasan, tanamannya dapat tumbuh dengan subur di berbagai daerah di Indonesia. Sehingga tidak heran jika Indonesia menjadi salah satu negara penghasil jahe terbesar di dunia. Jumlah produksi jahe di Indonesia meningkat dari tahun ke tahun. Pada tahun 2003, produksi jahe nasional adalah sebesar 112.290 ton. Dengan tingkat kenaikan produksi sebesar 3,28 \% tiap tahun maka tahun 2009 jumlah produksi jahe di 
Indonesia diperkirakan sebesar 136.388,1 ton dan pada tahun 2017 meningkat lebih banyak 120.000 dari tahun sebelumnya (Sukmawati \& Merina, 2019).

Salah satu daerah yang memiliki angka produksi jahe cukup tinggi adalah Daerah Istimewa Yogyakarta. Menurut data dari Badan Pusat Statistik (BPS) Daerah Istimewa Yogyakarta, poduksi jenis tanaman biofarmaka di Daerah Istimewa Yogyakarta (DIY), paling tinggi adalah jahe. Tahun 2018 produksi jahe di DIY mencapai 5.455.788 kuintal. Tingginya minat masyarakat dalam mengkonsumsi jahe terlihat dari harga jahe yang melunjak cukup drastis, dimana pada tahun 2020 harga jahe naik menjadi Rp46.000-50.000/kg untuk jahe biasa dari harga awal sebesar Rp25.000-33.000/kg,. Begitu pula dengan jahe merah yang awal nya hanya Rp40.000/kg naik menjadi Rp120.000/kg. Menurut beberapa sumber, kenaikan harga jahe ini dipicu karena kondisi Covid-19 yang tengah melanda Indonesia.

Berbicara mengenai tingginya minat konsumen terhadap suatu produk, maka menarik kiranya untuk melihat bagaimana preferensi konsumen terhadap produk tersebut. Secara sederhana preferensi konsumen dapat diartikan sebagai pilihan suka tidak suka oleh seseorang terhadap produk (barang atau jasa) dari berbagai alternatif yang ada (Anugraheni \& Kusdiartini, 2018). Preferensi konsumen muncul pada tahap dimana konsumen dihadapkan dengan berbagai macam pilihan produk atau jasa dengan berbagai macam atribut yang berbeda-beda (Putri \& Iskandar, 2017).

Atribut merupakan unsur-unsur yang terdapat dari suatu produk yang dipandang penting oleh konsumen, dan dijadikan dasar dalam pengambilan keputusan pembelian (Kotler, 2008). Atribut produk inilah yang akan membedakan antara produk yang ditawarkan oleh suatu perusahaan dengan produk sejenis yang ditawarkan perusahaan lain. Perbedaan atribut ini kemudian bisa menimbulkan perbedaan persepsi konsumen terhadap produk yang ditawarkan oleh berbagai perusahaan sehingga akhirnya dapat mempengaruhi konsumen dalam keputusan pembelian (L. Setyanto et al., 2017).

Atribut produk adalah unsur-unsur produk yang dipandang penting oleh konsumen dan dijadikan dasar pengambilan keputusan pembelian. Atribut produk 
Achmad \& Millaty, Atribut yang Menjadi Pertimbangan Konsumen Terhadap....

inilah yang akan membedakan antara produk yang ditawarkan oleh suatu perusahaan dengan produk sejenis yang ditawarkan perusahaan lain. Perbedaan atribut ini kemudian bisa menimbulkan perbedaan persepsi konsumen terhadap produk yang ditawarkan oleh berbagai perusahaan sehingga akhirnya dapat mempengaruhi konsumen dalam keputusan pembelian (Setyanto, 2017). Berdasarkan latar belakang ini, peneliti tertarik untuk meneliti mengenai atribut yang menjadi pertimbangan konsumen dalam keputusannya membeli produk minuman berbahan dasar ekstrak jahe. Penelitian ini dibatasi pada konsumen minuman kemasan yang berada di Kabupaten Sleman.

\section{METODE PENELITIAN}

Penelitian ini dilakukan di Kabupaten Sleman selama 3 bulan (Juni-Agustus 2021). Dikarenakan populasi masyarakat Sleman yang besar, maka peneliti mengambil sebagian saja sebagai sampel. Dimana sampel adalah sebagian dari populasi yang dianggap mewakili populasi (Simamora, 2004). Banyaknya jumlah sampel yang digunakan, dihitung menggunakan rumus Lemeshow. Hal ini dikarenakan jumlah populasi tidak diketahui atau tidak terhingga. Berikut rumus Lemeshow (1997) $: \mathrm{n}=\frac{z^{2} p(1-p)}{d^{2}}$

keterangan :

$\mathrm{n}=$ Jumlah sampel

$\mathrm{z}=$ Nilai standart $=1.96$

$\mathrm{p}=$ Maksimal estimasi

$\mathrm{d}=$ alpha $(0,10)$ atau sampling error $=10 \%$

Berikut penghitungan jumlah sampel dari rumus Lemeshow:

$\mathrm{n}=\frac{z^{2} p(1-p)}{d^{2}}$

$\mathrm{n}=\frac{1,96^{2}(0,5)(1-0,5)}{0,10^{2}}$

$\mathrm{n}=\frac{3,8416(0,25)}{0,01}$

$\mathrm{n}=96,04$

$\mathrm{n}=96$

Berdasarkan hasil perhitungan menggunakan rumus Lemeshow, diperoleh jumlah sampel sebanyak 96 responden. Penelitian ini menggunakan data primer dan 
data sekunder. Data primer dilakukan dengan menyebarkan kuisioner kepada responden secara acak (random sampling) sedangkan data sekunder diperoleh dari beberapa sumber referensi seperti buku dan jurnal. Data yang diperoleh selanjutnya ditabulasi dan dianalisis menggunakan alat bantu SPPS.

Terdapat dua belas atribut yang diteliti pada penelitian ini, antara lain harga, rasa, kemasan, informasi produk, kadaluarsa, praktis, merek, aman, promosi, kemudahan didapat, halal. Untuk mengetahui atribut apa saja yang menjadi pertimbangan konsumen dalam memutuskan untuk membeli minuma kemasan yang mengandung ekstrak jahe, dilakukan analisis uji binomial. Rumus uji binomial adalah sebagai berikut (Suliyanto, 2014):

$$
\mathrm{P}(\mathrm{x})=\frac{N}{x}
$$

Dimana:

$\mathrm{N}=$ Jumlah Pengamatan

$\mathrm{X}=$ Jawaban Sukses (Ya)

$\mathrm{P}=$ Probabilitas Jawaban sukses

$\mathrm{Q}=$ Probabilitas Jawaban Gagal

Dengan $\alpha=0,05$ dan derajat kebebasan $(\mathrm{dk})=\mathrm{k}-1$

\section{HASIL DAN PEMBAHASAN}

\section{Karakteristik Responden}

Berdasarkan hasil penelitian, diketahui jika konsumen minuman kemasan yang mengandung ekstrak jahe didominasi oleh perempuan, yaitu sebesar $53 \%$. Menurut (Kusmayadi, 2017), dalam sebuah keluarga, wanita merupakan pengelola keuangan yang pandai dalam mengatur keuangan rumah tangga. Sehingga tidak heran jika konsumen minuman kemasan didominasi oleh perempuan. Dilihat dari segi pendapatan, lebih dari 50\% responden memiliki tingkat pendapatan kurang dari 2 juta rupiah. Hal ini menunjukkan bahwa konsumen yang mengkonsumsi minuma kemasan di daerah Kabupaten Sleman, banyak dikonsumsi oleh masyarakat menengah ke bawah. Tabel 1 menunjukkan tingkat pendapatan responden dalam satu bulan. 
Achmad \& Millaty, Atribut yang Menjadi Pertimbangan Konsumen Terhadap....

Tabel 1. Tingkat Pendapatan Responden

\begin{tabular}{ccc}
\hline Pendapatan & Responden & Persentase \\
\hline$<2$ juta & 57 & $58 \%$ \\
$2-5$ juta & 29 & $30 \%$ \\
$5-7$ juta & 7 & $7 \%$ \\
$>7$ juta & 3 & $5 \%$ \\
\hline Jumlah & 96 & $100 \%$ \\
\hline
\end{tabular}

Sumber: Data Primer (2021)

Diketahui jika mayoritas responden membeli minuman ekstrak jahe paling banyak di toko kelontong sebanyak $41 \%$. Selanjutnya responden membeli minuman tersebut di minimarket sebanyak $25 \%$, di swalayan sebanyak $17 \%$, online $5 \%$, lainlain $13 \%$. Hal ini menunjukkan bahwa membeli secara langsung di toko, baik toko kelontong, mini market, maupun swalayan masih menjadi primadona konsumen minuman kemasan yang mengandung ekstrak jahe, dibandingkan jika membeli produk minuman tersebut secara online. Tabel 2 menunjukkan lokasi pembelian minuman kemasan mengandung ekstrak jahe.

Tabel 2. Tempat Memperoleh Minuman Ekstrak Jahe

\begin{tabular}{ccc}
\hline Kategori & Responden & Persentase \\
\hline Swalayan & 17 & $17 \%$ \\
Minimarket & 25 & $26 \%$ \\
Toko kelontong & 40 & $41 \%$ \\
Online & 5 & $5 \%$ \\
Lain-lain & 9 & $13 \%$ \\
\hline Jumlah & 96 & $100 \%$ \\
\hline
\end{tabular}

Sumber: Data Primer (2021)

Keputusan responden dalam membeli produk minuman mengandung ekstrak jahe, mayoritas dipengaruhi oleh orang tua sebanyak 32,3\%. Keluarga merupakan organisasi pembelian konsumen yang paling penting dalam masyarakat dan telah diteliti secara eksensif. Peranan anggota keluarga dalam pengambilan keputusan adalah sebagai inisiator, pemberi pengaruh, pengambilan keputusan, penyaring informasi, dan pembeli (Towoliu \& Tumbuan, 2017). Selain keluarga, keputusan konsumen dalam membeli sebuah produk dipengaruhi oleh teman sebanyak 28,1\%. Hal ini menunjukkan bahwa lingkungan terdekat konsumen memiliki peran penting di dalam keputusan konsumen dalam membeli sebuah produk. 
Media sosial juga memberikan pengaruh yang cukup besar dalam keputusan konsumen membeli produk minuman kemasan yang mengandung ekstrak jahe. Berdasarkan hasil penelitian, diketahui jika 25\% responden memperoleh informasi terhadap produk minuman tersebut dari media sosial. Media sosial saat ini mengubah cara konsumen berkomunikasi dan berbagi informasi kepada rekanrekannya. Sebagian besar konsumen menggunakan media sosial untuk mencari informasi sebelum melakukan pembelian. Ulasan di dalam media sosial dapat mendorong konsumen untuk melakukan pembelian. Konsumen yang memiliki pengalaman positif atas suatu produk dan membagikan pengalamannya di media sosial akan memiliki pengaruh tinggi terhadap orang lain yang sedang mencari produk yang sama (Indriyani \& Suri, 2020). Sedangkan peran media elektronik dalam keputusan konsumen membeli sebuah produk, memberikan pengaruh sebesar $13,5 \%$.

Tabel 3. Sumber Informasi untuk Memperoleh Minuman Esktrak Jahe

\begin{tabular}{lcc}
\hline \multicolumn{1}{c}{ Kategori } & Responden & Persentase \\
\hline Orang tua & 31 & $32,3 \%$ \\
Teman & 27 & $28,1 \%$ \\
Media sosial & 24 & $25 \%$ \\
Media elektronik & 13 & $13,5 \%$ \\
Lain-lain & 1 & $1,1 \%$ \\
\hline Jumlah & 96 & $100 \%$ \\
\hline
\end{tabular}

Sumber: Data Primer (2021)

Berdasarkan informasi yang diperoleh dari responden terpilih, diketahui jika $84 \%$ responden mengkonsumsi minuman kemasan mengandung ekstrak jahe dalam bentuk kemasan sachet. Sedangkan sisanya yakni sebanyak 16\% responden mengkonsumsi minuman kemasan mengandung ekatrak jahe dalam bentuk lainnya, seperti kemasan botol maupun kemasan kotak karton yang langsung dapat dikonsumsi. Sedangkan untuk merek yang dikonsumsi oleh responden cukup bervariasi, antara lain susu jahe, sidomuncul, anget sari, jahe merah, dan lain-lain. 
Achmad \& Millaty, Atribut yang Menjadi Pertimbangan Konsumen Terhadap....

\section{Atribut yang Menjadi Pertimbangan Konsumen terhadap Minuman Kemasan yang Mengandung Ekstrak Jahe}

Uji binominal digunakan pada data nonparametrik. Ada 2 prinsip dalam distribusi binomial yaitu bahwa setiap percobaan pada distribusi binomial hanya menghasilkan 2 kejadian yang berkomplemen seperti gagal/sukses, ya/tidak, berhasil/tidak berhasil dan setiap pengulangan bebas terhadap pengulangan berikutnya (Diana, 2017). Selain persyaratan di atas, uji binominal juga tidak membutuhkan asumsi bahwa data berdistribusi normal (Simamora, 2004). Hasil uji binomial pada penelitian ini, dapat dilihat pada tabel 4 .

Tabel 1. Hasil Analisis Uji Binominal

\begin{tabular}{|c|c|c|c|c|c|}
\hline \multicolumn{6}{|c|}{ Binomial Test } \\
\hline & Category & $\mathrm{N}$ & Observed Prop. & Test Prop. & $\begin{array}{l}\text { Exact Sig. } \\
\text { (2-tailed) }\end{array}$ \\
\hline \multirow[t]{3}{*}{ Harga } & Ya & 62 & 0,65 & 0,50 & 0,006 \\
\hline & Tidak & 34 & 0,35 & & \\
\hline & & 96 & 1,00 & & \\
\hline \multirow[t]{3}{*}{ Rasa } & $\mathrm{Ya}$ & 91 & 0,95 & 0,50 & 0,000 \\
\hline & Tidak & 5 & 0,05 & & \\
\hline & & 96 & 1,00 & & \\
\hline \multirow{3}{*}{ Kemasan } & Ya & 73 & 0,76 & 0,50 & 0,000 \\
\hline & Tidak & 23 & 0,24 & & \\
\hline & & 96 & 1,00 & & \\
\hline \multirow{3}{*}{$\begin{array}{l}\text { Informasi } \\
\text { produk }\end{array}$} & $\mathrm{Ya}$ & 81 & 0,84 & 0,50 & 0,000 \\
\hline & Tidak & 15 & 0,16 & & \\
\hline & & 96 & 1,00 & & \\
\hline \multirow[t]{3}{*}{ Kadaluarsa } & Ya & 88 & 0,92 & 0,50 & 0,000 \\
\hline & Tidak & 8 & 0,08 & & \\
\hline & & 96 & 1,00 & & \\
\hline \multirow[t]{3}{*}{ Praktis } & Ya & 62 & 0,65 & 0,50 & 0,006 \\
\hline & Tidak & 34 & 0,35 & & \\
\hline & & 96 & 1,00 & & \\
\hline \multirow[t]{3}{*}{ Merek } & $\mathrm{Ya}$ & 86 & 0,90 & 0,50 & 0,000 \\
\hline & Tidak & 10 & 0,10 & & \\
\hline & & 96 & 1,00 & & \\
\hline \multirow[t]{3}{*}{ Keamanan } & Ya & 47 & 0,49 & 0,50 & 0,919 \\
\hline & Tidak & 49 & 0,51 & & \\
\hline & & 96 & 1,00 & & \\
\hline \multirow[t]{3}{*}{ Promosi } & Ya & 91 & 0,95 & 0,50 & 0,000 \\
\hline & Tidak & 5 & 0,05 & & \\
\hline & & 96 & 1,00 & & \\
\hline \multirow{3}{*}{$\begin{array}{l}\text { Kemudahan } \\
\text { didapat }\end{array}$} & $\mathrm{Ya}$ & 90 & 0,94 & 0,50 & 0,000 \\
\hline & Tidak & 6 & 0,06 & & \\
\hline & & 96 & 1,00 & & \\
\hline
\end{tabular}




\begin{tabular}{llrrrr}
\hline \multicolumn{5}{c}{ Binomial Test } \\
\hline & Category & $\mathrm{N}$ & Observed Prop. & Test Prop. & $\begin{array}{r}\text { Exact Sig. } \\
\text { (2-tailed) }\end{array}$ \\
\hline Diskon & Ya & 47 & 0,49 & 0,50 & 0,919 \\
& Tidak & 49 & 0,51 & & \\
& & 96 & 1,00 & & \\
\hline
\end{tabular}

Sumber: Data Primer (2021)

Berdasarkan tabel 4, diketahui jika dari 96 responden yang diambil datanya, sebanyak 62 responden menganggap harga menjadi pertimbangan utama, 91 responden menganggap rasa menjadi pertimbangan utama, 73 responden menjawab kemasan mejadi pertimbangan utama, 81 responden memandang jika informasi produk yang terdapat pada kemasan menjadi pertimbangan utama. Sedangkan untuk atribut lainnya seperti kadaluarsa, praktis, merek, keamanan, promosi, kemudahan didapat, dan diskon berturut-turut terdapat sebanyak 88, 62, 86,47, 91, 90, dan 47 responden yang menganggap atribut tersebut menjadi pertimbangan utama.

Hasil analisis uji binomial, diketahui atribut diskon dan keamanan memiliki nilai signifikansi lebih dari 0,05 . Atribut diskon dan keamanan tidak menjadi pertimbangan utama konsumen di dalam keputusannya membeli produk minuman kemasan mengandung ekstrak jahe. Hal ini mungkin dikarenakan konsumen minuman kemasan sudah menganggap harga produk relatif lebih terjangkau dan konsumen sudah tidak meragukan lagi keamanan produk tersebut.

Atribut harga memiliki nilai signifikansi 0,006 atau kurang dari 0,05 yang memiliki arti harga menjadi pertimbangan utama konsumen dalam keputusan membeli produk minuman kemasan mengandung ekstrak jahe. Menurut (Hanifawati et al., 2017), konsumen dengan pendapatan lebih rendah memiliki pilihan alternatif produk yang terbatas, terutama diduga menyangkut pertimbangan harga, ukuran, dan volume produk. Konsumen dengan pendapatan lebih tinggi akan melakukan pembelian lebih kompleks yang berefek pada tingkat keterlibatan dan perilaku pembeliannya.

Atribut kemasan, informasi produk, kadaluarsa, dan merek juga memiliki nilai signifikansi kurang dari 0,05. Artinya atribut kemasan, informasi produk, kadaluarsa, dan merek menjadi pertimbangan konsumen dalam membeli produk 
Achmad \& Millaty, Atribut yang Menjadi Pertimbangan Konsumen Terhadap....

minuman kemasan mengandung ekstrak jahe. Hal ini sesuai dengan penelitian yang dilakukan oleh (Sucipto et al., 2016), dimana dikatakan jika atribut kemasan memberi pengaruh positif dan signifikan terhadap kepuasan konsumen. Di dalam kemasan, terkandung informasi produk, kadaluarsa, dan merek yang tentunya menjadi atribut yang penting di dalam pengambilan keputusan konsumen. Atribut rasa, promosi dan kemudahan didapat juga memiliki nilai signifikansi kurang dari 0,05 . Tentunya atribut rasa, promosi, dan kemudahan didapat merupakan faktor penting yang perlu diperhatikan oleh produsen karena hal ini juga menjadi pertimbangan utama konsumen di dalam keputusannya membeli sebuah produk minuman kemasan yang mengandung ekstrak jahe.

\section{SIMPULAN}

Mayoritas konsumen minuman kemasan yang mengandung ekstrak jahe mayoritas adalah wanita sebesar 53\%. Konsumen minuman kemasan ini adalah konsumen dengan tingkat pendapatan yang rendah, dimana lebih dari 50\% responden memiliki penghasilan kurang dari Rp2.000.000,00 atau lebih kecil dari UMR Kabupaten Sleman sebesar Rp2.001.000,00. Selanjutnya berdasarkan analisis uji binomial, diketahui jika atribut yang menjadi pertimbangan konsumen di dalam keputusannya membeli produk minuman kemasan yang mengandung ekstrak jahe adalah atribut harga, rasa, kemasan, informasi produk, kadaluarsa, merek, promosi dan kemudahan didapat.

\section{DAFTAR PUSTAKA}

Anugraheni, D. T., \& Kusdiartini, V. (2018). Preferensi Konsumen Terhadap Media Sosial Dalam Mencari Dan Membeli Produk Secara Online. Jurnal Ekonomi Dan Bisnis, 21(2), 8-17.

Diana, D. (2017). Distribusi Binomial Sebagai Estimasi Probabilitas Kesuksesan Pada Uji Coba Kualitas Layanan Sistem Informasi. Jurnal Ilmiah Matrik, 19(3), 227-236. http://journal.binadarma.ac.id/index.php/jurnalmatrik/article/view/390 
Hanifawati, T., Suryantini, A., \& Mulyo, J. H. (2017). Pengaruh Atribut Kemasan Makanan Dan Karakteristik Konsumen Terhadap Pembelian. Agriekonomika, 6(1). https://doi.org/10.21107/agriekonomika.v6i1.1895

Indriyani, R., \& Suri, A. (2020). Pengaruh Media Sosial Terhadap Keputusan Pembelian Melalui Motivasi Konsumen Pada Produk Fast Fashion. Jurnal Manajemen Pemasaran, 14(1), 25-34. https://doi.org/10.9744/pemasaran.14.1.25-34

Kotler, Philip. (2008). Manajemen Pemasaran Edisi 12 Jilid 2. Jakarta: Indeks.

Kusmayadi, R. C. R. (2017). Proses pengambilan keputusan dalam keluarga (Studi mengenai pekerja wanita dalam industri pengolahan tembakau Pr. Tali Jagaddi desa Gondowangi kecamatan Wagir kabupaten Malang). Gender Equality: International Journal of Child and Gender Studies, 3(1), 1-10.

Putri, N. E., \& Iskandar, D. (2017). Analisis preferensi konsumen dalam penggunaan social messenger di kota bandung tahun 2014 (studi kasus : line, kakaotalk, wechat, whatsapp). Jurnal Manajemen Indonesia, 14(2), 110-126. https://doi.org/10.25124/jmi.v14i2.356

Setiawan, A., \& Pujimulyani, D. (2018). Antioksidan dan tingkat kesukaan minuman instan kunir. Inovasi Pangan Lokal Untuk Mendukung Ketahanan Pangan, 1(1), 1-7.

Setyanto, L., Arifin, Z., \& Sunarti, S. (2017). PENGARUH ATRIBUT PRODUK TERHADAP KEPUTUSAN PEMBELIAN (Survei Pembeli Apple IPhone pada Mahasiswa/Mahasiswi S1 Fakultas Ilmu Administrasi Program Studi Ilmu Administrasi Bisnis Angkatan 2013/2014 Universitas Brawijaya Malang). Jurnal Administrasi Bisnis S1 Universitas Brawijaya, 46(2), 1927.

Setyanto, L. E. (2017). ( Survei Pembeli Apple iPhone pada Mahasiswa / Mahasiswi S1 Fakultas Ilmu Administrasi Program Studi Ilmu Administrasi Bisnis Angkatan 2013 / 2014 Universitas Brawijaya Malang ). Administrasibisnis.Studentjournal.Ub ‥, 46(2), 19-27. http://administrasibisnis.studentjournal.ub.ac.id/index.php/jab/article/view $/ 1805$

Simamora, Bilson. (2004). Panduan Riset Perilaku Konsumen. Jakarta: PT Gramedia Pustaka Utama.

Simamora, Bilson. (2004). Riset Pemasaran Falsafah, Teori, dan Aplikasi. Jakarta: PT Gramedia Pustaka Utama. 
Achmad \& Millaty, Atribut yang Menjadi Pertimbangan Konsumen Terhadap....

Sucipto, S., Herdiana, Y. E. P., \& Mustaniroh, S. A. (2016). Analisis Keterkaitan Atribut Kemasan Teh Siap Saji Dan Etnik Terhadap Kepuasan Konsumen. Jurnal Teknik Industri, 6(3), 233-241. https://doi.org/10.25105/jti.v6i3.1548

Sukmawati, W., \& Merina, M. (2019). Pelatihan Pembuatan Mipelatihan Pembuatan Minuman Herbal Instan Untuk Meningkatkan Ekonomi Warganuman Herbal Instan Untuk Meningkatkan Ekonomi Warga. Jurnal $\begin{array}{llll}\text { Pengabdian } \quad \text { Kepada } & \text { Masyarakat, }\end{array}$ https://doi.org/10.24114/jpkm.v25i4.14874

Suliyanto. (2014). Statistika Non Parametric dalam Aplikasi Penelitian. Yogyakarta: Penerbit Andi.

Towoliu, J. E. S., \& Tumbuan, Willem. J. F. A. (2017). Pengaruh Faktor Pribadi dan Faktor Keluarga Terhadap Keputusan Pembelian di Rumah Makan Waroeng Tepi Laut, Manado. Jurnal EMBA, 5(2), 308-322. 